\title{
Education of Tolerant Personality of a Future Specialist as the Social-Pedagogical Phenomenon
}

\author{
Tokkulinova Gulnar Kaztaevna ${ }^{1}$, Assylova Raushan Omarovna ${ }^{1}$, Tleuzhanova Kuralay Askerkhanovna ${ }^{1}$, \\ Burkitbaeva Anar Zhanarbekovna ${ }^{1} \&$ Kazhieva Nurgul Erezhepovna ${ }^{1}$ \\ ${ }^{1}$ Pedagogical Science, Zhetysu State University, Kazakhstan \\ Correspondence: Tokkulinova Gulnar Kaztaevna, Pedagogical Science, Zhetysu State University, Zhansugurov \\ Street, 187(a), 040000 Taldykorgan, Kazakhstan.
}

$\begin{array}{lc}\text { Received: October 14, } 2014 & \text { Accepted: November 24, } 2014 \quad \text { Online Published: January 28, } 2015 \\ \text { doi:10.5539/ies.v8n2p169 } & \text { URL: http://dx.doi.org/10.5539/ies.v8n2p169 }\end{array}$

\begin{abstract}
The article raises the problem of education of tolerance in students as a social and pedagogical phenomenon and stresses the importance and urgency of this problem at the present stage of society development. The author examines the theoretical basis and the possibility of development of tolerant relations in vocational education as a special value of human rights, which states respect for the opinions of others, to various forms of self-expression and human individuality. The definition of «tolerance» offers diversified understanding of the content and the value of this characteristic. The study of the theoretical sources allowed the authors to outline the objectives and activities to promote tolerance. Solutions for selected tasks considered arsenal of interactive approaches in educational work. Analysis of the available resources and opportunities of higher education has led the authors to the idea of independent structural unit in the structure of university that encourages tolerance, high morality, which would be, according to the authors, the quality indicators of education.
\end{abstract}

Keywords: education of tolerance, human rights, self-expression, hermeneutics

\section{Introduction}

The problem of tolerance is one of the most actual and complicated in the modern science. The significant increasing of the researches in this sphere in the end of XX-in the beginning of XXI century connected with the increasing acts of violence, terrorism, exacerbate religious and ethnic conflicts. Attention of researchers to the issues of tolerance is explained by pronounced tendency humanization of science, increasing interest in the problems of personality development of the growing person, highlighting important task of education (Praliyev, 2009).

Cultural heritage, its popularization and study, wide application of fundamental social and human sciences of Kazakhstan within the educational space for education of the modern youth will be the guarantor for this new generation of professionals, which will have a high level of national consciousness, personal and professional qualities and universal values. Updating the education process of a new generation of citizens, both in substantial and operational aspects, will enable young people to solve the personal and social problems through the development of their own potential, co-existing in a team and with a team and communicating with others. The recent educational and social-psychological research, outlining all the main levels and ranges of personal orientation of the rising generation, reveal the need to form their readiness to carry out the public duties and use their civil rights. Only a person with the developed self-consciousness, who has a high capacity for self-reflection, who has mastered the social laws, shows a sense of civic duty and responsibility. The problem of effectiveness of interpersonal communication in the context of understanding and implementation of their rights and responsibilities is especially important. It is important to create the conditions for education of young people, which would help them to take a conscious position of the citizen of their state. The problems is how we can semantically and methodically improve the education of a young person, facilitate his mastering the laws of social space and necessity of normative behavior, develop self-reflection, thus realizing his personal capacity in accordance with the achievement of generally useful goals (Manual \& Gurov, 2004).

Method «Prediction of the situation». During the conversation, the teacher offers to suggest how could develop one or another conflict situation. In this case the search is conducted out of the situation (Namazbayeva, 2005). 
Method «Improvisation on a free theme». Students choose the theme in which they are strongest and which gives them a certain interest is transferred to the new conditions of the event, in its own way interpret the meaning of what is happening (Bergh et al., 2010).

\section{The Main Part}

Concept of tolerance is being studied by many sciences: philosophy, ethics, political science, education and psychology. The word tolerance has almost the same meaning in different languages: in English-willingness to be tolerant, in French-treatment, when person thinks and acts differently than you do, in Chinese-being in relation to other gorgeous, Arabian-mercy, patience, compassion, Russian-ability to accept the other as he or she is. In its broad sense of the word, tolerance means, tolerance for others' opinions and actions, the ability to treat them without irritation. In this sense, tolerance is a rare trait. Tolerant person respects the beliefs of others, not trying to prove his exclusive right. Wave of terrorism has swept around the world, the terrorist attacks in all Russian and Kazakhstan's cities, the growth of organized crime, the decision for personal, commercial, political and other disputes involving weapons, corruption and bureaucratic arbitrariness undoubtedly hinder uphold the principles of tolerance. Nevertheless, the formation of a tolerant society in the expansion at this point of time gaining its turn. Everybody has already become obvious urgency of the problems of tolerance, so their solution is given to close attention. Special attention is paid to the development of tolerance at schools. So, as a child still needs to be explained about the importance of tolerance in our world. School is focusing on the formation of children tolerance: held events, celebrations, which are aimed at upbringing all children and adolescents, class hours devoted to the issues of tolerance (Gitlin et al., 2013).

The first, who raised the issue of tolerance in the context of international relations, was academician, director of the Institute of Ethnography and Anthropology Tishkov, talking about the necessity of «inter-ethnic tolerance». Tolerance, by his definition - is personal and social characteristics, which involves the realization that peace and social environment - and therefore multidimensional views on the world are different and should not be reduced to uniformity, or in one's favor. He determined that tolerance is expressed on a psychological level (internal installation and relationship between the individual and collective) and political level (the action or materialized form) (Girard \& Johnson, 2010).

Tolerance is respect, acceptance and appreciation of the rich diversity of our forms of expression and ways of being human. It is fostered by knowledge, openness, communication and freedom of thought, conscience and belief. Tolerance - harmony in diversity. This personality trait is part of a humanistic orientation and identity is determined by its value attitude towards others. It is set up for a certain type of relationship, which is manifested in the actions of human personality. By tolerance, we mean realized conscious personal commitment to action to achieve humanistic relations between individuals and groups having different world, different values, and patterns of behavior (Grawemeyer et al., 2012).

Tolerance is not passive, it active. It is not concession, condescension or indulgence. Tolerance - is primarily an active attitude prompted by recognition of the universal human rights and fundamental freedoms under any circumstances of human. Tolerance should be exercised by individuals, groups, states (Girard and Johnson, 2008). In my opinion a tolerant person is a person who knows himself and to understand other people. When we talk about the tolerant person, we mean the rejection of his own views, values and ideals. Tolerance should not be reduced to indifference, conformity, denial of self-interest, and suggests on the one hand, the stability as a person's ability to realize their personal position, and the other - flexibility as the ability to respect the positions and values of others (Johnson et al., 2001).

Today, the task of tolerance education should permeate all activities of social institutions and especially those who have a direct impact on the formation of the child's personality.

Tolerance category can be viewed from different perspectives: as ethical-philosophical concept as the principle of relations between followers of different ideological concepts, convictions and beliefs, as a method of social and political decision-making actions and so on. Distinguish different forms of tolerance-personal, social, manifested in morals, customs, mentality, mind state, reflected in law, political practice (Girard \& Johnson, 2010).

You cannot be tolerated in the case of distorted scientific data or information proven experimentally. If you cannot clearly estimate what is better that optimally, where the truth is, it is advisable to treat respectfully and peacefully dissent, remaining at their beliefs. Tolerance is the desire to establish and maintain positive interactions with people who differ from us by some characteristics or do not adhere to generally accepted opinions. Tolerance is shown by the active moral position and tendency to dialogue and understanding with representatives of different cultural, national, ethnic, religious, or social environment; by the ability to establish 
the relationship that does not cause harm to other individuals at implementation of one's own freedom; by understanding and acceptance of diversity of other people's personality as the «self-sufficient and self-worth» persons (King et al., 2002).

According to results of the current research, it was found out that interpersonal tolerance as a holistic social-psychological phenomenon in its specific displays has significant positive links with the statuses of students, acting as the significant others in-group interactions. The higher the intensity of positive components of interpersonal tolerance, the higher the status of a student in the group as a significant other (Hagood et al., 2002).

Table 1.

\begin{tabular}{|c|c|c|c|}
\hline Identity & Zero level & First level & Second level \\
\hline Theintellectual & $\begin{array}{l}\text { absence of knowledge of } \\
\text { essence of tolerance and } \\
\text { aspiration to their } \\
\text { receiving; }\end{array}$ & $\begin{array}{l}\text { knowledge of essence of } \\
\text { tolerance is sketchy, isn't } \\
\text { systematized; }\end{array}$ & $\begin{array}{l}\text { knowledge of essence of } \\
\text { tolerance is systematized, } \\
\text { work on their replenishment } \\
\text { is carried out; }\end{array}$ \\
\hline Themotivational & $\begin{array}{l}\text { absence of aspiration to } \\
\text { manifestation of tolerance } \\
\text { in communication; }\end{array}$ & $\begin{array}{l}\text { manifestation of tolerant } \\
\text { qualities in communication } \\
\text { has incidental character; }\end{array}$ & $\begin{array}{l}\text { communication is based in } \\
\text { compliance with the } \\
\text { principles of tolerance; }\end{array}$ \\
\hline Thestrong-willed & $\begin{array}{l}\text { there is no aspiration to } \\
\text { implementation of } \\
\text { self-checking behind the } \\
\text { behavior in pedagogical } \\
\text { situations; } \\
\text { doesn't show and doesn't } \\
\text { seek for manifestation of } \\
\text { respect of foreign opinion; } \\
\text { aspiration } \\
\text { implementation to } \\
\text { self-checking behind the } \\
\text { behavior; }\end{array}$ & $\begin{array}{l}\text { manifestation of empathy in } \\
\text { communication, } \\
\text { implementation of } \\
\text { self-checking behind } \\
\text { emotions is carried out } \\
\text { depending on a situation } \\
\text { and its participants; }\end{array}$ & $\begin{array}{l}\text { the emotional and steady } \\
\text { attitude towards all } \\
\text { participants of educational } \\
\text { process, continuous } \\
\text { self-checking behind the } \\
\text { emotions; manifestation of } \\
\text { empathy in communication; }\end{array}$ \\
\hline
\end{tabular}

Among the main criteria and indicators of psychological tolerance are:

1) Social activity-readiness to work together in various social and ethnic situations in order to achieve the assigned goals and build the constructive relationships in society;

2) Behavior divergence-the ability to solve unconventionally the common problems and challenges;

3) Mobility-the ability to change quickly the strategy and tactics;

4) Empathy-a way of understanding the other person, based not on comprehension of the problems of another person, but on the effort to respond emotionally to the problem of this person;

5) Personal stability-the formation of social-moral motives of the individual in the process of interaction with people from different ethnic and social groups.

Tolerance is understood as respectful and proper comprehension of rich diversity of our world's cultures, forms and ways of expression of human personality. It is fostered by knowledge, openness, communication and freedom of thoughts, conscience and beliefs. The process of tolerance education presupposes the ability of one or both parties to compromise and still maintain the respect for each other, which, of course, does not mean indifference, permissive attitude to the inhuman, illegal actions in the behavior and deeds of any participant of the dialogue, regardless of ethnicity. One of the major social institutions that promote formation of a tolerant person in the modern society is education. Tolerance as a personal trait is not inherent in a man originally and it may never be shown, if it is not trained and formed specially. The social-pedagogical goal of tolerance education is aimed at development of recognition of the view point, diversity of cultural differences within the framework of universal human rights and freedoms and thus it ensures the development of independent thinking, critical interpretation and making opinions based on moral values (Eagleton, 2004). 
Education of tolerant personality of a future specialist is one of the priorities in the social-pedagogical work. Updating the content of educational process should be based on the qualitatively new idea of the status of tolerant education, which takes into account national-regional features of local traditions, activates stimulation of educational methods diversity, improves the effectiveness of university mechanisms and establishes and maintains the balance between the state, family and social education. Education as a process of interaction, but not an impact is associated with tolerance (patience and indulgence). This is training such behaviors and responses that do not harm other person and take into account characteristics and attitudes of this person. The process of education is based on the idea of voluntarily and consciously chosen attitude to the behavior and actions of others, i.e., tolerance. Teaching assumes acquaintance with the variety and originality of ethnic cultures of those, who live nearby. Education of tolerance is the development of tolerant behavior skills and, first of all, the development of ability of young people to see the conflict, identify the reasons for it and ways of solution. Youth education should be directed to formation of a humane person with inherent combination of personality expressions and tolerant orientation, characterized by comprehension of the civic duty, diligence, responsibility, professional and human culture and culture of interaction with other people (Kuzminskyy, 2013).

The following activities can facilitate the solution of these tasks:

1) Combination of universal, national, cultural and ethno-specific values, covering the main aspects of social and cultural life and self-determination in the education system, what forms the basis for tolerance education;

2) Education of a Kazakhstan citizen through the study of history, traditions, culture, life and work of outstanding individuals;

3) Combination of socially significant and individually acceptable component of the content, methods and forms of educational activity, its openness, diversity of the forms and methods of training and self-study, which increases the social and cultural competence of student personality (Zyazyun, 2005).

Modern social-pedagogical science and practice pay a lot of attention to the interactive methods of work. They are the specific type of learning activity, aimed not so much at reinforcement and replication of existing ideas, beliefs, prejudices, skills and abilities, but on learning and getting new information. There is a large arsenal of interactive approaches in the educational work, which help to awaken the interest to the new through «immersion» into the situation, emotional empathy with what is going on. Relative to the students the teacher acts as a kind of «bandmaster» in this complicated process, directing and organizing the training activities aimed at expansion of students' knowledge about the principles of tolerance, the necessity to be ready for active creative activity in the modern, multicultural and multinational environment. In this regard, there is a need for relevant educational supplies, which will help us to systematize the knowledge of tolerance in its broad concept on the basis of scientific evidences. All the above mentioned lead to the idea of creating the independent educational department in the structure of high schools with the following functions (Kurlyand et al., 2005):

The Scientific-methodological Function is aimed at:

1) Complex regulatory-technological support to the educational process by means of the purposeful work on creation of the regulatory base as well as the bank of educational technologies, their systematization and implementation at institutions of higher education;

2) Scientific development of the programs for sociological and psychological diagnostics, which allow qualified monitoring of the personal state of students and social-cultural environment of their interaction;

3) Development of performance criteria for the educational work of the university as a variety of educational standards aimed at real assessment of educational work in a particular institution and comparative analysis of its performance in the Republic (Benavent, 2003).

Educational Function: Development of educational and planning documentation for educational aspects of psychological and educational training and retraining of teachers of higher education and direct participation in organization and performance of these trainings.

Information Function: Promotion of conceptual ideas, trends and technologies of educational work with students through conferences, seminars, round tables as well as reviewing and preparation of publications about high school education.

The problem of tolerance education should unite different people, first of all, the specialists in different areas and levels-psychologists, teachers, educators, managers, leaders and ordinary employees as well as representatives of different age groups (children and adolescents, adults and youth). Analysis of the tolerance phenomenon allows the conclusion about its increasing role as a factor of harmonious development of society and requires further 
research for identification of the most effective mechanisms for its formation (Garcia-Nieto, 2004).

Content of socio-educational activities in terms of secondary school.

School and the family, the social environment of the child, as a rule, do not engage in the alignment of individual strategies of interaction with the person and with the world. Family forms the external socially-acceptable forms of child behavior and the school are principally engaged in intellectual development. Important constituent of the aesthetic moral education - the development of tolerance among students (Santana, 2003).

Within the formation and development of tolerance is necessary to create appropriate scientific school «educational atmosphere», which implies respect for otherness of another, respect for minority by the majority, the rights of each individual, the responsibility of the person in front of others. And in light of the formation and development of national tolerance is necessary to expand the social circle of students to learn about other cultures, traditions to communicate with representatives of other cultures...constructive, cooperative dialogue within the student-centered approach to social and psychological adaptation requires experimental and innovative total activity of pupils, teachers and parents. Upbringing any moral quality (including tolerance) largely depends on the individual pupil: existing morals behavior, ethical guidelines, and the development of intellectual and emotionally volitional, the level of development of mental processes, character traits, personal experience of relationships, the presence of natural development and spiritual abilities, etc. The formation of tolerance should be considered as gender and, above all, differences in personality traits social behavior. Fostering tolerance is largely due to the influence of the social environment. The less tolerant environment for the child, the more difficult the process of its formation. It is therefore necessary to examine the social environment and move into it the ideas of tolerance, picking up for this by appropriate forms, methods, practice (Benavent, 2003).

Development of tolerance requires the construction of the educational process at two interrelated levels: informational (available knowledge about tolerance, its manifestations, about the multidimensionality of human existence, the formation install on tolerance) and behavioral (ability to use skills of tolerant interaction), make up the whole. The main criterion of formation of tolerance should be the ability to constructively interact with tolerant people and groups with some differences.

Dialogization of educational area and reliance on cooperation as the leading type of interaction are required to comply with the principle of tolerance. Cooperation through dialogue should be priorities in the structure of interaction: student-student, student-teacher, and student-teacher-environ student-teacher culture.

Forming tolerant attitudes and behaviors, it's necessary to create conditions for pupil's reflection occurred to them changes and analyzing emerging relationships in the team, family and society.

\section{Conclusion}

Upbringing of tolerant person is currently one of the most important social problems. Difficulty understanding that naturally occur in people due to racial, ethnic, age, gender and other differences in the situation of permanent intensive interaction, lead to increased psychological stress, cultural intolerance, aggression ethnic, religious extremism, which cannot be overcome without the decisive contribution by the psychological science. We need to educate tolerance from an early age. Their tolerant personality will help to determine their future orientation, their choice of peaceful coexistence and mutual understanding, but not the conflicts, as a priority. Culture of dialogue, tolerance and high level of morality determine the manners of any person and for the modern institution it should be one of the qualitative characteristics of education development.

Findings: Analysis of psychological and pedagogical literature suggests that the concept of tolerance, although the majority of sources identified with the concept of patience, has a brighter active orientation. Tolerance - is not passive, unnatural conquest of views, opinions and actions of others, not submissive patience, and active moral position and psychological readiness for the sake of mutual tolerance. Considering the phenomenon of tolerance through dialogue, we conclude that tolerance, being the basis of communication, however, is not reducible to it. Communication aimed at achieving maximal generality community playing in turn aim of tolerance, which is designed by its internal mechanisms to turn the "other" as an object in a full-fledged partner in dialogue - in the subject. On the other hand, having a dual nature, being and unity of opposites, tolerance plays a dual role in the structure of communication: it is characterized by the emotional component of the process of communication within and objectively reflects the relationship of subjects through the complex behavioral responses based on the rational comprehension of relations subjects.

Considering the humanistic foundation of education, we conclude that the system of human relations of teacher with children divided into three inseparable parts: understanding, recognition and acceptance of the child. The 
teacher should never forget that the concept of tolerance for it is identified primarily as an active moral position and psychological readiness for tolerance in the name of mutual understanding between the teacher and his students.

Also in this work, there were scrutinized the basic criteria and indicators of tolerance: the stability of personality, empathy, divergent thinking, mobility behavior, social activity, and tolerance functions: providing global, regulatory, psychological, educational, communicative, creative, culture retained.

The help to the teacher in the process of promoting a culture of tolerance has pedagogical hermeneutics - the science that studies the problem of understanding, interpretation and detection of deep meanings in educational activities in general, and in educational practice, particularly.

The role of hermeneutics is to make for educational activities, educational orientation, keeping in mind primarily such an important moment, as goal setting. Key questions: What is the purpose? For what? - Constant attention of hermeneutics. Without indicating the goals of education, it is impossible to look for means to achieve these goals. Broadly, hermeneutics today understands as art understanding and interpretation of the spiritual manifestations of human activity, which is one of the most important moments in the upbringing of tolerant person. Pedagogical method of hermeneutics helps to accept and understand each child, develops pedagogical intuition, tolerance to overcome a situation of «misunderstanding», the teacher brings to solving urgent problems of humanization of children's lives. Understanding always starts with the identification of misunderstanding, followed by surgery to overcome it by resorting to the teacher's own intellectual, emotional, cultural and teaching experience, followed by reflection as a movement in the senses. Identification, recognition of their professional misunderstanding-a very difficult pedagogical problem.

In conclusion, we can say that in a multicultural environment should become a schoolteacher and a spokesman for the carrier universal cultural values. The training period should provide future teacher the opportunity to not only acquire deep domain at a level that corresponds to the task of modernization of education, but also to build a sense of value-orientation.

\section{References}

Benavent, J. A. (2003). Reflexionessobre el futuro de la orientaciónpsicopedagógicainmersaenunaencrucijada sociocultural. Revista Españolade Orientación y Psicopedagogía, 14(1), 41-59. http://dx.doi.org/10.5944/reop.vol14.1.2003.11604

Bergh, L., Ros, A., \& Beijaard, D. (2010). Feedback during active learning\& elementary school teachers' beliefs and perceived problems (p. 257).

Cerri, S. A., Clancey, W. J., Papadourakis, G., \& Panourgia, K. (Eds.). Intelligent Tutoring Systems: 11th International Conference, ITS 2012, Chania, Crete, Greece, June 14-18, 2012. Proceedings (pp. 262-267). Springer-Verlag, Berlin.

Eagleton, T. (2004). "Marxist Criticism.” In D. Walder (Ed.), Literature in the Modern World: Critical Essays and Documents (pp. 243-251). Oxford: Oxford University Press.

García-Nieto, N. (2004). Nuevascompetenciasdocentes: el rolorientadoren el actual profesorado. Conferencia inaugural Curso 2004-2005. Madrid: Universidad Complutense.

Girard, S., \& Johnson, H. (2008). Designing and evaluating affective open-learner modeling tutors. In Proceedings of the 7th International Conference on Interaction Design and Children-IDC '08 (pp. 13-16). NewYork: ACM. http://dx.doi.org/10.1145/1463689.1463706

Girard, S., \& Johnson, H. (2010). Designing affective computing learning companions with teachers as design partners. In Proceedings of the 3rd International Workshop on Affective Interaction in Natural Environments-AFFINE '10 (pp. 49-54). New York: ACM. http://dx.doi.org/10.1145/1877826.1877840

Girard, S., \& Johnson, H. (2010). What do children favor as embodied pedagogical agents? In V. Aleven, J. Kay, \& J. Mostow (Eds.), Intelligent Tutoring Systems, Pt 1, Proceedings (Vol. 6094, pp. 307-316). Springer. http://dx.doi.org/10.1007/978-3-642-13388-6_35

Gitlin N., William C., \& Bruce W. (2013). A non-pharmacologic approach to address challenging behaviors of Veterans with demantia: Description of the tailored activity program-VA randomized tral (p. 342). http://dx.doi.org/10.1186/1471-2318-13-96

Grawemeyer, B., Johnson, H., Brosnan, M., Ashwin, E., \& Benton, L. (2012). Developing an embodied pedagogical agent with and for young people with autism spectrum disorder. 
http://dx.doi.org/10.1007/978-3-642-30950-2_33

Hagood, M., Stevens, L. P., \& Reinking, D. (2002). What Do TheyHave to Teach Us? In D. E. Alvermann (Ed.), Adolescents and Literacies in a Digital World (pp. 68-83). NewYork: PeterLang.

Johnson, H., Johnson, P., Wild, P., May, J., \& Gamble, T. R. (2001). Modelling multiple and collaborative tasks. In J. Vanderdonckt, A. Blanford, \& A. Derycke (Eds.), Proceedings of IHM-HCI 2001 (Vol. 2, p. 217). Toulouse: Cepadues-Editions.

King, J. R., \& O’Brien D. G. (2002). Adolescents' Multiliteracies and Their Teachers' Needs to Know: Toward a Digital Détente. In D. E. Alvermann (Ed.), Adolescents and Literacies in a Digital World (pp. 40-50). NewYork: PeterLang. http://dx.doi.org/10.1215/15314200-2002-007

Kurlyand, Z., Hmelyuk, R., \& Semenov, A. et al. (2005). Pedagogy of Higher School: Manual. In Z. Kurlyand (Ed.), Revised and add (2nd ed. p. 399). Znannya, Kyiv.

Kuzminskyy, A. (2013). On the Development of Pedagogical Excellence: Prerequisites and Preconditions. American Journal of Educational Research, 1(11), 456-463.

Manual, E., \& Gurov, V. N. (2004). Forming Tolerant Individuality in Polyethnic Educational Environment (p. 127). Moscow.

Namazbayeva, Zh. I. (2005). Cultural-Historical Psychology as the basis of Education Humanization. In Proceedings of International Conference, Almaty (p. 138).

Praliyev, S. Zh. (2009). Relevant Problems of Forming Individualities of Future Specialists. Journal of Pedagogy and Psychology, 158.

Santana, L. (2003). Orientación educativa e intervención psicopedagógica. Cambian los tiempos, cambianlas responsabilidades profesionales. Madrid: PsicologíaPirámide.

Zyazyun, I. (2005). Spiritual factors of elitist personality. Proceedings of the J. Komenskyy International Slavic Academy of Education, Bendery, 3, 115-122.

\section{Copyrights}

Copyright for this article is retained by the author(s), with first publication rights granted to the journal.

This is an open-access article distributed under the terms and conditions of the Creative Commons Attribution license (http://creativecommons.org/licenses/by/3.0/). 